\title{
Sobre o 'Colocar em Questão' na Filosofia de Foucault: Relação entre Transcendental, Historicidade e Experiência
}

[On the 'Putting into Question' in Foucault's Philosophy: Relation between Transcendental, Historicity and Experience]

\section{Jefferson Martins Cassiand ${ }^{\circledast}$}

Resumo: Este artigo propõe uma reflexão sobre o 'colocar em questão' na filosofia de Foucault. Nesse sentido, a interpretação a Kant feita por Foucault auxilia a entender como seu pensamento 'coloca em questão' uma pergunta que forneça um referencial de pesquisa. Para tanto, faz-se necessário apresentar as bases da filosofia de Kant e a maneira como Foucault as interpreta. Com isso, pode-se entender melhor as pontuações feitas por Béatrice Han e elaborar um argumento sobre o 'colocar em questão' na filosofia de Foucault. Assim, a questão kantiana: "o que é o Homem?" se encontra transformada pela questão de Foucault: "quem somos nós?" .

Palavras-chave: Foucault; Kant; Transcendental; Historicidade; Experiência

\begin{abstract}
This article proposes a reflection on the 'put into question' in Foucault's philosophy. In that perspective, Foucault's interpretation of Kant contributes to understand how to 'put into question' an issue may provide a referential to research. Therefore, it is essential to present the basis of Kant's philosophy and the way Foucault interprets them. Hence, it is possible to understand better the notes written by Béatrice Han and elaborate an argument about to 'put into question' in Foucault's thought. Thus, the Kantian question: "what is Man?" is transformed by the question of Foucault: "who are we?" .

Keywords: Foucault; Kant; Transcendental; Historicity; Experience
\end{abstract}

Em uma de suas últimas entrevistas, Foucault afirma que o interesse de sua pesquisa "foi criar uma história dos diferentes modos pelos quais, em nossa cultura, os seres humanos se tornam sujeitos. Meu trabalho [Foucault] lidou com três modos de objetivação que transformam os seres humanos em sujeitos", de modo que "não é o poder, mas o sujeito, que constitui o tema geral de minha pesquisa" (FOUCAULT, 1994,

${ }^{*}$ Doutorando em Filosofia pela Universidade de Brasília (UnB). Mestre em Filosofia pela UnB, e Licenciado em Filosofia pela Pontifícia Universidade Católica de Campinas. E-mail: jeffmarcas@hotmail.com. ORCID: https://orcid.org/0000-0001-9853-6599. 
IV, p.223) $)^{1}$. Em três décadas dedicadas ao estudo (1954-84), Foucault perseguiu seu interesse por diferentes maneiras de pesquisar, seja investigando vários domínios de saber (psiquiatria, economia, linguística); seja forjando seu próprio instrumental conceitual (épistémè, dispositivo, biopoder); seja confrontando as racionalizações excessivas no governo de nossas práticas sociais (enclausuramento da loucura, marginalização da delinquência, repressão da sexualidade).

Certamente, para a (pretensão de) realização de seus objetivos, Foucault manteve certo número de questões com as quais teve que lidar durante seu percurso filosófico. Duas dessas questões foram recuperadas por Foucault da filosofia de Kant; e assim podem ser definidas: o pensamento crítico e o diagnóstico do presente. Ao pensamento kantiano está claramente reservado dois momentos de destaque no estudo foucaultiano. O primeiro momento pode ser definido pela produção da Thèse Complémentaire ao doutoramento de Foucault (1961), publicada postumamente, e pelo destaque dado a Kant na obra Les mots et les choses (1966). Nesse primeiro momento, Foucault dedica uma grande importância à antropologia kantiana e seus desdobramentos, atribuídos como o limiar (arqueológico) de nossa época. $\mathrm{O}$ segundo momento se refere à fase final da produção intelectual de Foucault, principalmente com uma espécie de texto-testemunho, Qu'est-ce que les Lùmieres? (1984), no qual o autor comenta o opúsculo de Kant de 1784, Beantwortung der frage: was ist Aufklärung? Nesse segundo momento de interpretação a Kant, Foucault exorta a maneira de filosofar que se ocupa com o tempo presente. Com isso, a atenção inicial à antropologia kantiana se encontra reformulada por uma reflexão sobre a atitude crítica com relação ao acontecimento da atualidade.

Conhecido o itinerário filosófico, eis que, então, tem-se a importância do tema sobre o 'colocar em questão' na filosofia de Foucault. Pode-se dizer que o primeiro momento da pesquisa de Foucault pretende 'colocar em questão' uma suspeita sobre as ilustres questões kantianas: O que posso saber? O que devo fazer? O que cabe esperar? Como observa Foucault, o próprio Kant condiciona estas questões a custa de uma ultima ratio: o que é o Homem? Não obstante, torna-se interessante notar que desta suspeita

\footnotetext{
${ }^{1}$ Quando presente, os algarismos romanos I, II, III, IV se referem ao volume/tomo da coletânea Dits \& Écrits.
} 
manifestada por Foucault, parece haver um acolhimento, e tão logo uma apropriação do autor, no que diz respeito ao problema que a filosofia kantiana se propõe a elucidar. Isso significa dizer que a filosofia de Kant 'coloca em questão' uma pesquisa precisamente orientada: quais são as condições de possibilidade da experiência em geral? Segundo Foucault, esta questão kantiana sobre as condições de possibilidade desloca todo o eixo investigativo do saber moderno, promovendo novas bases para a prática filosófica.

Para Béatrice Han, a filosofia de Foucault se propõe a examinar tais condições de possibilidade, porém de um modo histórico. Esta é uma afirmação perspicaz da autora (e não menos controversa) de grande interesse ao propósito deste texto, uma vez que aponta para o fato de como 'colocar em questão' pode ser fundamental para compor um plano de pesquisa, visto que, de fato, há uma ocupação de Foucault com as 'condições de possibilidade' em sua filosofia. Ao analisar a interpretação de Han, pode-se compreender que Foucault manobra com a questão sobre as condições de possibilidade kantianas (acima elencadas) sintetizada na questão: 'o que é o Homem?', não apenas tentando inseri-la a fórceps em um positivismo, mas procurando criticá-la como um acontecimento do atual. O objetivo deste texto é refletir sobre o modo de 'colocar em questão' uma pergunta que forneça um referencial de pesquisa. Para tanto, o argumento se desenvolve em quatro segmentos: o primeiro, expõe as bases da filosofia de Kant; o segundo, apresenta as maneiras como Foucault lhes interpreta. O terceiro, comenta as pontuações feitas por Han; e o quarto, elabora um argumento sobre como 'colocar em questão' a filosofia de Foucault.

\section{O triedro da filosofia de Kant}

Utilizando uma figura foucaultiana que ilustra a configuração do saber na épistémè moderna (FOUCAULT, 1966, capítulo X), pretendo designar com a ideia de um triedro da filosofia de Kant as bases que formam o fundamento e caracterizam o pensamento kantiano. Nesse sentido, destacam-se três temas reconhecidos e debatidos por Foucault em seus textos e obras, a saber: razão crítica, filosofia transcendental e o Esclarecimento [Aufklärung].

A razão crítica (ou pensamento crítico) é, sem dúvida, um dos maiores legados da filosofia de Kant, com grande influência na filosofia posterior, como no caso da teoria crítica da Escola de Frank- 
furt. Inclusive o próprio Foucault se identifica ligado a esta tradição do pensamento kantiano. Já no primeiro parágrafo da sua genial obra, Crítica da Razão Pura (1787), Kant assim estabelece as condições para uma razão crítica:

A razão humana, num determinado domínio de seus conhecimentos, possuiu o singular destino de se ver atormentada por questões, que não pode evitar, pois lhe são impostas por sua natureza, mas às quais também não pode dar respostas por ultrapassarem completamente as suas possibilidades (KANT, 2001, p.29).

Ainda no prefácio da mencionada obra, Kant registra a situação que o pensamento de seu tempo parece lhe reservar. Primeiro, o dogmatismo, com suas mil metafísicas para além dos limites da experiência. A seguir, o ceticismo, com suas suspeitas incessantes conduzindo ao relativismo da aparência. Por fim, o indiferentismo, que tentar evitar a ambos (dogmatismo e ceticismo), porém acaba por ser uma atitude antinatural, uma vez que quer privar a razão de sua própria natureza de questionar o conhecimento humano.
Para Kant, tal situação da filosofia lhe parece insuficiente e inconveniente diante do prestígio e progresso que goza a ciência newtoniana. A saída proposta por Kant é tornar a razão um tribunal, no qual ela atue ao mesmo tempo como juiz e como réu: "esse tribunal outra coisa não é que a própria Crítica da Razão Pura" (KANT, 2001, p.31). Assim, Kant delega à razão crítica uma tarefa que "assegure as pretensões legítimas [da razão] e, em contrapartida, possa condenar-lhes todas as presunções infundadas" (ibidem).

Para tanto, é conhecida a revolução copernicana evocada por Kant (2001, p.44), de modo que, ao invés de buscar modos metafísicos de determinar o objeto em si, a razão crítica deve averiguar as condições de possibilidade que tal objeto possui para um sujeito cognoscente, a fim de definir a legitimidade e o limite da razão tanto no campo teórico quanto no prático. A diferença promovida por Kant em relação à concepção escolástica se deve à substituição da razão como instrumento de contemplação divina, para uma acepção ativa, isto é, a razão crítica é uma atividade de um sujeito racional. Contudo, importa observar que esta atividade deve ser entendida como propedêutica. Kant elogia a lógica por manter seu caráter limitado, que, ao mesmo 
tempo, autoriza e obriga a determinar para si mesma os limites de seu conhecimento. Do mesmo modo que o conhecimento da lógica prepara o pensamento científico, também deve a crítica da razão preparar os limites que tornam seu uso legítimo. É nesse sentido que Kant propõe seu método à crítica, de modo "a poder abranger totalmente o campo dos conhecimentos que lhe pertencem (...) porquanto apenas se refere a princípios e limites de seu uso, que são determinados pela própria crítica", concluindo com a advertência de "nunca nos atrevermos a ultrapassar com a razão especulativa os limites da experiência" (KANT, 2001, p.50). Portanto, com relação à razão crítica, Kant afirma que "podemos considerar [a crítica] uma propedêutica do sistema da razão pura, uma ciência que se limite simplesmente a examinar a razão pura, suas fontes e limites" (KANT, 2001, p.79).

A propedêutica da razão crítica é necessária para a realização da filosofia (ou idealismo) transcendental (KANT, 1987, p.64). Kant assim define o termo transcendental: "chamo transcendental a todo conhecimento que em geral se ocupa menos dos objetos, do que do nosso modo de os conhecer, na medida em que este deve ser possível a priori. Um sistema de conceitos desse gênero deveria denominar-se filosofia transcendental" (KANT, 2001, p.79). $\mathrm{O}$ aspecto transcendental qualifica um tipo de conhecimento que não concerne aos objetos, mas às formas e aos conceitos puros a priori e à aplicação que fazem aos objetos. Trata-se de um estudo de fundamentação e, consequentemente, de objeção à metafísica dogmática, na medida em que somente visa justificativas para o próprio conhecimento.

Kant considera que a "filosofia transcendental é a ideia de uma ciência para qual a crítica da razão pura deverá esboçar arquitetonicamente o plano total, isto é, a partir de princípios (...) [estabelecer] todas as partes que constituem esse edifício" (KANT, 2001, p.80). Importante notar, nesse caso, a relevância do termo ciência aplicado à filosofia transcendental. Na tradição do idealismo alemão ao qual se filia Kant, normalmente se reserva o termo crítica para o exame das condições de possibilidade, seja de um campo de conhecimento, seja de um objeto em geral. O termo doutrina avalia a capacidade de produzir conhecimento, ensiná-lo e informá-lo. Já o termo ciência designa uma pretensão de que o próprio conhecimento seja capaz de prover sua autofundamentação, ou seja, sem recorrer aos ar- 
tifícios e sortilégios para além de suas condições de possibilidade. Daí a advertência de Kant para a crítica da razão, segundo a qual "a esta ciência não se deverá dar o nome de doutrina, antes o de crítica da razão pura e sua utilidade (...) será apenas negativa, não servirá para alargar a nossa razão, mas tão-somente para clarificar, mantendo-a isenta de erros, o que já uma grande conquista" (KANT, 2001, p.79).

A noção de ciência aplicada à filosofia transcendental qualifica um saber sistemático, o qual Kant chama de arquitetônica. Isso significa que, para ser considerada como ciência, a filosofia transcendental deve estar sistematizada em um conjunto organizado (organon) segundo conformidade a fins estabelecidos por regras universalmente válidas. Nesse sentido, a filosofia transcendental, em vista das pretensões de Kant, se outorga o direito de declarar um ultimato: "todos os metafísicos estão, solenemente e em conformidade com a lei, suspensos de suas funções até que tenham respondido de modo satisfatório: como são possíveis conhecimentos sintéticos $a$ priori?" (KANT, 1987, p.42). Cabe à filosofia transcendental, então, determiná-los; tarefa que a conduz imputar-se questões que coincidem com o campo das condições de possibilidade. Ao final de a
Crítica da razão pura, Kant define as questões que a razão está autorizada e obrigada a tentar responder por seu próprio esforço; tratase das três celebres questões kantianas: "todo o interesse da minha razão (tanto especulativa quanto prática) concentra-se nas seguintes três interrogações: 1. Que posso saber? 2. Que devo fazer? 3. Que me é permitido esperar?" (KANT, 2001, p.651). Não obstante, em seus cursos sobre lógica, Kant estabelece uma quarta e derradeira questão que sistematiza qual o fim para as três questões anteriores; tal questão é: 'o que é o Homem?'. Enfim, a filosofia transcendental não pode evadir-se do esforço de tentar responder as questões que a própria razão humana se autoriza e obriga a 'colocar em questão'.

A partir da propedêutica da razão crítica e da arquitetônica dos princípios da filosofia transcendental, o pensamento de Kant se permite fazer interrogações acerca das condições de possibilidades do saber, do dever e do julgar (KANT, 1987, p.78), estudados respectivamente em cada uma das obras Crítica de Kant. Estas interrogações somente se apresentam possíveis em conformidade a fins, para o qual Kant assevera o próprio Homem. Nesse sentido, a última obra preparada por Kant para publicação, $A n^{-}$ 
tropologia em sentido pragmático (1798), se ocupa precisamente com a questão: 'o que é o Homem?'. Não se trata, porém, de realizar uma observação sobre o que é o Homem na natureza, uma vez que Kant dirige seu estudo sobre o que o Homem pode e deve fazer de si mesmo (KANT, 1991, p.07). Ora, pode-se dizer que para Kant a filosofia transcendental, ao 'colocar em questão' a reflexão sobre o Homem de seu próprio tempo, denomina-se Esclarecimento [Aufklärung]. É em uma breve resposta ao jornal alemão Berlinischen Monatsschrift, em 1784, que esse tema se destaca. Mais do que uma época de calendário, Kant estabelece o Esclarecimento como um programa cultural de autorrealização do próprio Homem.

Dois aspectos do Esclarecimento são apresentados por Kant. $\mathrm{O}$ primeiro aspecto afirma que a "libertação da superstição chamase Esclarecimento", de modo que, todavia, "vê-se logo que o Esclarecimento na verdade in thesis é fácil, in hypotesi, porém, é uma coisa difícil e lentamente realizável" (KANT, 2012, p.149). Esta é a definição de Esclarecimento seguida pela teoria crítica de Adorno e Horkheimer (1985). O segundo aspecto apresentado por Kant diz que "Esclarecimento é a saída do homem de sua menoridade, da qual ele próprio é culpado" , sendo essa menoridade "a incapacidade de fazer uso de seu entendimento sem a direção de outro indivíduo", cuja causa é a "falta de decisão e de coragem de servirse de si mesmo sem a direção de outrem" (KANT, 2013, p.63). Sapere aude! Ouse saber! exorta o lema kantiano do Esclarecimento. O autor declara que "para este Esclarecimento, porém, nada mais se exige senão a liberdade", que tenha conformidade a fins do "uso público de sua razão deve ser sempre livre e só ele pode realizar o Esclarecimento entre os homens" (Idem, p.65).

Dessa forma, se o uso público da razão representa a saída do homem de seu estado tutelado, pelo qual ele próprio é responsável, então o Esclarecimento representa, enquanto uso público da razão, o resultado manifesto na história da razão crítica e da filosofia transcendental, pois para Kant "nossa época é a época da crítica, a qual tudo tem de submeter-se" , uma vez que, "a razão só concebe [justificativa] a quem pode sustentar o seu livre e público exame" (KANT, 2001, p.31). Logo, a publicidade da razão diz respeito à emancipação do Homem em todos os seus direitos, sua condição capaz e a plena consciência de si. Em certa medida, a última obra preparada por Kant, Antropologia em sentido 
pragmático, aponta para o estágio final do processo de emancipação social do Esclarecimento: o cidadão do mundo (PEREZ, 2010) representa e determina a tarefa de uma filosofia transcendental: possibilitar fazer uso público de sua razão em todas as questões.

Pode-se dizer, enfim, que a razão crítica, a filosofia transcendental e o Esclarecimento formam as bases pelas quais o potencial do pensamento kantiano pode se desenvolver. Reconhecer esse triedro que fundamenta as bases da filosofia kantiana favorece a compreensão do que seja, talvez, a própria função de filosofar. Tal função que vincula e veicula pelo pensamento de Kant passa inevitavelmente pelo modo que o filósofo consegue 'colocar em questão' uma pergunta que permita estabelecer um referencial de pesquisa. Enfim, destaca-se que esses três temas abordados manifestam o interesse de Foucault pela filosofia kantiana 2, com isso, importa observar a relevância empenhada por Foucault, na interpretação a Kant, seja justamente refletir sobre o que a filosofia transcendental consegue 'colocar em questão'.

\section{Interpretações e apropriações de} Foucault a Kant

Como mencionado, o pensamento foucaultiano reserva dois momentos de destaque à filosofia de Kant. Vale advertir que somente no caso da Thèse Complémentaire (1961) Foucault realiza uma exegese do texto kantiano; algo que, no entanto, não inibe que Foucault expresse seu ponto de vista. Nos demais textos dedicados ao exame da filosofia kantiana, o autor francês parece atuar de forma mais autônoma, sem se deter em um comprometimento de fornecer uma detalhada explicação sobre a filosofia de Kant. Em tal sentido, Foucault se apropria de termos kantianos em favor de seu próprio pensamento. Nesse caso, pode-se dizer que Foucault pretende 'colocar em questão' o próprio empenho da filosofia kantiana. Por essa razão, parece adequado proceder com dois momentos de análise: primeiro, o momento voltado para as interpretações de Foucault a Kant; e a seguir, o momento dedicado às apropriações dos termos kantianos que Foucault incorpora à sua filosofia.

A primeira interpretação de relevância feita por Foucault a Kant aparece em uma longa introdução, seguida pela tradução para o idi-

\footnotetext{
${ }^{2}$ Sobre esse tema, sugiro o opúsculo de Frédéric Gros e Jorge Dávila, Michel Foucault lector de Kant, 1998.
} 
oma francês publicada em 1964 da obra Anthropologie in pragmatischer Hinsicht. Contudo, na publicação editorial da tradução, Foucault retira a introdução apresentada como Thèse Complémentaire, substituindo-a por uma 'notícia histórica' (FOUCAULT, 1994, I, p.288-93) 3 . Pode-se dizer que em sua Thèse Complémentaire Foucault procede por três tipos de comentários: comentários de contextualização acerca das diversas versões recebidas pela Antropologia em sentido pragmático; comentários exegéticos que apresentam os principais conceitos e temas tratados por Kant; e comentários críticos que buscam estabelecer uma relação entre a fase Crítica e a obra da Antropologia. Oportunamente, é este último tipo de comentário que importa verificar.

$\mathrm{O}$ argumento Foucault parte da ideia de que a antropologia kantiana funciona como passagem da propedêutica crítica à realização da filosofia transcendental. Para o filósofo francês, a filosofia transcendental é atingida pela questão: 'o que é o Homem?' (FOUCAULT, 2008, p.22). A leitura de Foucault busca na fase Crítica o limite do campo investigação da obra Antropologia, cujo pres- suposto adotado é de que existe um fundamento estrutural entre a fase Critica e antropologia (FOUCAULT, 2008, p.15). É preciso, no entanto, advertir que Foucault constrói grande parte de seu argumento tomando por referência o auxílio do Manual do curso de lógica geral e do Opus Postumum, textos compilados a partir de anotações de colaboradores e sem a revisão de Kant, algo que pode enfraquecer seu argumento 4 .

Foucault acena para o paradoxo do pensamento kantiano, pois a proposta propedêutica da fase Crítica prepara a vinda de uma Antropologia; porém, a Antropologia tem que se submeter à Crítica (FOUCAULT, 2008, p.22). Isso significa que toda a antropologia kantiana pressupõe a razão crítica, enquanto exame dos limites, mas é a filosofia transcendental que, por seu caráter sistemático de ciência, lhe confere um princípio organizador. Tal princípio organizador já não é mais condição de possibilidade a priori (determinado pela razão pura); o princípio deve estar enraizado na empiricidade: este princípio, segundo Foucault, é a finitude (Idem, p.28). Por isso, comenta Foucault: "a antropologia encontrar-se-á dupla-

\footnotetext{
${ }^{3}$ Foucault jamais volta a mencionar a Thèse Complémentaire, que só foi publicada postumamente.

${ }^{4}$ A esse respeito, vale mencionar que Thèse Complémentaire traz uma valiosa apresentação do que foi a recepção da antropologia kantiana na França; não obstante, na ocasião de sua arguição, as dificuldades desse projeto foram acusadas pela banca examinadora, sugerindo a não publicação da obra, tal como a encontramos hoje.
} 
mente submetida à Crítica: enquanto conhecimento, às condições que ela fixa e aos domínios da experiência que ela determina; enquanto exploração da finitude, às formas primeiras e não ultrapassáveis que a Crítica manifesta" (Idem, p.32).

Ao buscar uma relação entre a Crítica e a Antropologia, Foucault 'coloca em questão' o dilema kantiano: como responder se a filosofia transcendental pode fundamentar e justificar a finitude, sem recorrer a uma filosofia do Absoluto? Foucault retoma a Crítica da razão pura para expor a ilusão transcendental, segundo a qual a razão se sente naturalmente atraída por ideias transcendentes (Deus, alma, mundo, liberdade). Segundo Kraemer, "a ilusão [transcendental] consiste em tomar como coisas reais o que são apenas ideias da razão, daí a necessidade da [razão] crítica para indicar os limites em que seu uso é legítimo" (KRAEMER, 2008, p.102). Logo, a ilusão transcendental reside em considerar a mesmo forma de conhecimento dos postulados das ideias da razão como se fossem experiências.

Ao final da Thèse Complémentaire, Foucault assinala uma ilusão antropológica que acomete a filosofia pós-kantiana, proveniente da exigência conflitante de uma razão crítica (exame dos limites da experiência) e a arquitetônica de uma filosofia transcendental (princípios a priori da experiência). Nesse caso, a finitude do Homem deve ser requisitada para fundar-se em si mesma a base legítima de conhecimento, para não violar as normas da razão crítica. Ademais, a finitude também não pode ser desprezada, como em geral faz a metafísica, das condições de possibilidade constituintes da existência humana (FOUCAULT, 2008, p.33). A resultante dessa ilusão antropológica é a aplicação da finitude retroagindo sobre si mesma. Foucault encerra sua Thèse Complémentaire afirmando a necessidade de se recusar todas as antropologias filosóficas modernas (diga-se, o humanismo), nas quais o ponto de partida e o horizonte concreto são definidos pela ilusão antropológica acerca de 'o que é o Homem’. Com isso, as ciências do Homem já estariam contaminadas pela incapacidade de exercer sobre a ilusão das antropologias filosóficas um pensamento verdadeiramente crítico.

Ao contrário do ostracismo de décadas recebida pela Thèse Complémentaire, a obra de 1966, Les mots et les choses, alçou o nome de Foucault aos best-sellers e aos círculos de debates, muito em razão do frisson causado pela polêmica suspeita da morte do Homem e da mudança de paradig- 
mas (CUSSET, 2008, p.35). Como visto, na tradução Anthropologie du point du vie pragmatique (1964), Foucault faz constar uma 'notícia histórica', a qual se encerra com a seguinte nota: "as relações do pensamento crítico e da reflexão antropológica serão estudados em uma obra ulterior" (FOUCAULT, 1994, I, p.293, nota). Ora, Les mots et les choses é a obra subsequente publicada por Foucault, e guarda interessantes relações com o desfecho da Thèse Complémentaire, como sugere Miller: "Era sua não publicada Thèse Complémentaire sobre a Antropologia de Kant, a semente da qual surgirá finalmente Les mots et les choses" (MILLER, 1995, p.186).

Não obstante, Les mots et les choses traz significativos acréscimos em relação a Thèse Complémentaire. Um deles diz respeito ao domínio de investigação; o objeto de interesse de Foucault não é o conhecimento pragmático, mas o saber. Por isso, ainda que Kant desempenhe um papel fundamental nas análises de Foucault, é o conceito de épistémè o tema central da obra. Outra novidade se refere ao nível da análise; em vez de enfatizar a relação entre CríticaAntropologia, o autor destaca a relação denominada empíricotranscendental. Além disso, a ilusão antropológica que encerra a Thèse Complémentaire ocupa posi- ção semelhante em Les mots et les choses, agora designada como sono antropológico. Enfim, a filosofia de Kant ocupa um lugar estratégico na arqueologia foucaultiana, pois a antropologia kantiana serve de base sobre a qual se desenvolve o que o pensador francês chama de analítica da finitude.

Em Les mots et les choses, as referências a Kant aparecem no sétimo e no nono capítulos. No sétimo capítulo (Ideologia e Crítica; as sinteses objetivas), Foucault trata de uma questão fundamental para sua pesquisa arqueológica, a saber, os modos de objetivação. Segundo o autor, a obra Crítica de Kant apresenta o modelo que define os modos de conhecer da épistémè moderna (FOUCAULT, 1966, p.253-56). A obra Crítica interroga os fundamentos e os limites do conhecimento, remetendo às próprias condições de possibilidade que tornam o conhecimento possível, isto é, o sujeito cognoscente. Foucault assinala uma analogia entre Destutt de Tracy e Kant, a saber, a emergência da função das sínteses objetivas nos modos de conhecer. Descartadas as ideias inatas, é preciso reconhecer que o conhecimento é um processo adquirido e limitado; trata-se, então, de assegurar como as sínteses objetivas são possíveis. Para Foucault, em função das sínteses objetivas faz-se ne- 
cessária a filosofia transcendental. Por isso, há uma necessidade no pensamento moderno de "fundar as sínteses [objetivas] no espaço da representação e pela obrigação correlativa, simultânea, mas logo dividida contra si mesma" a fim de poder "abrir o campo transcendental da subjetividade e constituir inversamente, para além dos objetos, esses 'quasetranscendentais' que são a Vida, o Trabalho e a Linguagem" (FOUCAULT, 1966, p.252). Logo, o pensamento moderno está tecido com as ideias da filosofia transcendental kantiana; nas palavras de Foucault:

Põe assim a descoberto um campo transcendental em que o sujeito, que jamais é dado na experiência (pois não é empírico), mas que é finito (pois não tem intuição intelectual), determina em sua relação com um objeto $=x$ todas as condições de experiência em geral; é a análise do sujeito transcendental que extrai o fundamento de uma síntese [objetiva] possível entre as representações (FOUCAULT, 1966, p.256; Cf. KANT, 2001, p.171).
Pode-se dizer que esse comentário de Foucault reproduz a ideia central da dedução transcendental kantiana, a qual pode ser assim formulada: para uma filosofia transcendental, as condições de possibilidade do objeto devem ser as mesmas e simultâneas com as condições de possibilidade da experiência (KANT, 2001, p.151). Para Foucault, nessa asserção reside a questão com a qual se ocupa a filosofia moderna, desde a fenomenologia e o existencialismo, até o positivismo e o estruturalismo. A conclusão é que a partir de Kant, os problemas da filosofia são os de responder positivamente como "os domínios empíricos se ligam às reflexões sobre a subjetividade, o ser humano e a finitude, assumindo valor e função de filosofia tanto quanto de redução da filosofia ou de contra-filosofia" (FOUCAULT, 1966, p.261).

Ora, uma vez reconhecida a épistémè moderna como o momento de formulação da filosofia transcendental, em Les mots et les choses, nono capítulo (analítica da finitude; sono antropológico), Foucault examina também suas consequências. O ponto de partida para a análise foucaultiana é a constatação de que "todo o campo do pensamento ocidental (...) vê-se constituir-se uma analítica da finitude e da existência humana, e em oposição a 
ela (mas em uma oposição correlativa) uma perpétua tentação de construir uma metafísica da vida, do trabalho e da linguagem" (FOUCAULT, 1966, p.328). Analítica da finitude significa que "o homem, na analítica da finitude, é um estranho duplo empíricotranscendental, porquanto é um ser tal que nele se tomará conhecimento do que torna possível todo conhecimento", visto que "o limiar de nossa modernidade não está situado no momento em que se pretendeu aplicar ao estudo do homem métodos objetivos, mas no dia em que se constitui um duplo empírico-transcendental a que se chamou homem" (FOUCAULT, 1966, p.329; $C f$. no mesmo sentido, p.355).

A analítica da finitude concerne à relação empíricotranscendental, e nesse ponto a antropologia kantiana aparece como a base para o exame de Foucault. Trata-se de identificar a atribuição ao Homem como sujeito que conhece e objeto de seu conhecimento, o que Foucault chama de pensamento do Mesmo, isto é, a repetição da positividade (saber instituído) no domínio transcendental (condições de possibilidade).

Pela repetição do positivo no fundamental, que toda essa analítica da fini- tude - tão ligada ao destino do pensamento moderno - vai desdobrar-se: é aí que se verá sucessivamente o transcendental repetir o empírico, o cogito repetir o impensado, o retorno da origem repetir seu recuo (FOUCAULT, 1966, p.326).

Essa afirmação significa que a busca pela resposta à questão: 'o que é o Homem?' se vê tomada pela confusão pendular entre a positividade do saber (vigente e instituído como tal) e a investigação fundamental (suas condições de possibilidade). Ora, se por um lado Foucault constata que "a Antropologia constitui talvez a disposição fundamental que comandou e conduziu o pensamento moderno desde Kant até nós" (FOUCAULT, 1966, p.353); por outro lado, as consequências são que "nessa Dobra [empíricotranscendental] a filosofia adormeceu de um novo sono, não mais o do Dogmatismo, mas o da Antropologia" (FOUCAULT, 1966, p.352).

Percebe-se que a ilusão antropológica evocada na Thèse Complémentaire ressurge com o tema do sono antropológico. Contudo, a diferença reside no fato de Foucault não se limitar a uma análise interna ao pensamento de Kant, 
pois agora situa-o como o limiar da épistémè moderna, de modo a examiná-lo em relação às outras formas de saber (biologia, economia, filologia). Nesse ponto, podese dizer que Foucault apresenta um diagnóstico quando reconhece que o pensamento moderno resvala em uma antropologia, ao menos silenciosamente, que the reserva o limite de direito de todo o conhecimento (FOUCAULT, 1966, p.261). Tem-se, então, um perigo ao 'antropologizar' o pensamento, isto é, conceber ao Homem o fim último de todas as questões: "a 'antropologização' é, em nossos dias, o grande perigo interior do saber" (FOUCAULT, 1966, p.359). Este perigo vislumbrado por Foucault é um sinal característico em obras posteriores a Les mots et les choses, o qual poder-se-ia chamar de uma 'vontade de saber' como legitimadora de práticas e técnicas de saber-poder. Tal vontade de saber pode conduzir a um pernicioso processo de normalização, no qual as relações de poder do saber científico do Homem reduzem a potência do ser humano, sobretudo no que diz respeito ao cuidado ético. Enfim, se Foucault identifica uma relação entre a filosofia transcendental e a antropologia kantiana em Les mots et les choses, é preciso dizer que o próprio pensamento foucaultiano se nutre do legado de Kant, e em certa medida, se apropria das questões colocadas pela filosofia transcendental e a antropologia kantiana.

Enfim, considerando as apropriações dos termos kantianos que Foucault incorpora à sua filosofia, Les mots et les choses não reserva apenas críticas à antropologia kantiana. $\mathrm{O}$ tema central da obra, a épistémè, se configura sobre as condições históricas de possibilidade para o espaço do saber (FOUCAULT, 1966, p.13). Em um ponto de vista mais radical, poder-se-ia dizer que Les mots et les choses vem 'colocar em questão' a própria questão kantiana: 'o que posso saber?', porém por meio de outra maneira de indagar: mas como o saber se torna possível? Nesse caso, Foucault indiscutivelmente rejeita a subjetividade como uma instância doadora de sentido, e também evita fazer uma epistemologia da verdade, isto é, avaliar as normas e justificativas de um domínio de saber. Em seu lugar apresenta as práticas discursivas que podem produzir o sentido que se atribui ao sujeito (FOUCAULT, 1994, I, p.789821). Trata-se de realizar uma arqueologia do saber, a qual Foucault assim define: "empresa na qual se tenta desfazer as últimas sujeições antropológicas" (FOUCAULT, 1969, p.25).

$\mathrm{Na}$ fase arqueológica do pensa- 
mento foucaultiano é flagrante o esforço do autor para distinguir a idade clássica (séculos XVIIXVIII) da era moderna (séculos XIX-XX). Basicamente, épistémè é um conceito forjado para esta finalidade. No entanto, Foucault atenta que a noção geral da épistémè não deve ser confundida com uma maneira de dividir a história, uma visão de mundo (Weltanschauung) ou uma teoria sobre a racionalidade ocidental (FOUCAULT, 1994, I, p.676). Épistémè remete antes a um espaço de dispersão no qual se formam regularidades discursivas. Importa observar que o conceito de épistémè envolve em si mesmo um modo de inquirir sobre as condições de possibilidade. Certamente, nisso há uma influência da filosofia de Kant, mas que se deve ao modo de 'colocar em questão' uma interrogação filosófica. Nesse caso, também deve-se destacar a influência de Lacan para a démarche (linha de raciocínio) foucaultiana, uma vez que se trata de estudar como as formas de saber estão ordenadas na linguagem, e assim evitar recorrer aos universais antropocêntricos. Assim como na teoria lacaniana do inconsciente, também a épistémè está estruturada como linguagem (LACAN, 1973, p.23). Logo, Foucault se distancia de Kant na medida em que não faz da consciência-de-si a condição de possibilidade do saber; tal condição se deve às práticas discursivas (FOUCAULT, 1969, p.236-40).

As condições de possibilidade epistêmicas são definidas a partir dos modos de objetivação. Pode-se dizer que em Les mots et les choses, Foucault trabalha com três modos de objetivação conjuntamente: a empiricidade, a positividade e a historicidade. Isso significa que o autor retira as condições de possibilidade epistêmica desses três domínios da objetivação. As empiricidades abordadas ao longo de Les mots et les choses são a vida, o trabalho e a linguagem; pode-se dizer que tais empiricidades representam as necessidades do ser humano enquanto ser vivente, produtor e falante, ou ainda, apontam para as dimensões do biológico, do socioeconômico e do simbólico. Como diz Foucault: "um homem é tanto aquele que vive, fala e trabalha, quanto aquele que conhece a vida, a linguagem e o trabalho, enfim aquele que pode ser conhecido à medida que vive, fala e trabalha" (FOUCAULT, 1994, I, p.501). Nesse sentido, as empiricidades da vida, do trabalho e da linguagem atuam como condições de possibilidade de experiência com as quais o ser humano se mantém dependente, como as necessidades do corpo, as relações de produção e os meios de comunicação. Sendo condi- 
ções de possibilidade de experiência, as empiricidades se referem às diversas práticas e discursos que transformam historicamente os modos do homem se relacionar consigo mesmo (vida), com seu meio (trabalho) e com o outro (linguagem). Trata-se de condições nas quais certas experiências humanas possibilitam determinados objetos de saber (por exemplo, 'patologias' como a "delinquência" , "homossexualidade" , "loucura"

) definidos por uma percepção cultural que tende a ser entendida como predisposição natural.

As transformações no domínio das empiricidades ocorrem na medida em que surge uma nova positividade do saber. De certo modo, a positividade é o que torna possível as práticas discursivas (ciência, filosofia, arte, política) ingressarem em um regime de verdade $5^{5}$. Quando um discurso pode ser classificado como verdadeiro ou falso, o discurso sobre certo objeto ou experiência, se 'positiva', recebe um status que o caracteriza e o autoriza. Segundo Foucault, o saber "em sua positividade, torna possível um jogo de opiniões simultâneas e aparentemente contraditórias. É essa rede que define as condições de possibilidade de um debate ou de um problema, ela é a portadora da historicidade do saber" (FOUCAULT, 1966, p.89). Nesse sentido, pode-se dizer que a positividade estabelece as condições de possibilidade de exercício do saber, visto que implica na disputa pelo próprio 'direito' de exercer o saber (FOUCAULT, 2012, p.102). Para Foucault, a positividade "define um espaço limitado de comunicação" no qual os "jogos de influências podem ser exercidos de um autor a outro, ou o domínio das polêmicas explícitas" (FOUCAULT, 1969, p.166-67)6. Em Les mots et les choses, o autor apresenta três regimes da positividade; um referente à épistémè clássica, e dois à épistémè moderna. As positividades do saber clássico são: história natural, análise das riquezas e gramática geral; as positividades do saber moderno são: biologia, economia e filologia; sendo que estas fundam as ciências humanas: psicologia, sociologia e análise literária. Segundo Foucault, "essas formas de positividade (e as condições de exercício da função enunciativa) definem um campo em que (...) desempenha o papel do que se poderia chamar de a priori histórico" (FOUCAULT, 1969,

\footnotetext{
5 O termo "regime de verdade" é característico dos textos da fase genealógica de Foucault (anos 1970-80); porém, pode-se dizer que esta noção já está presente na referência à positividade.

6 Citação levemente alterada.
} 
p.167).

Há ainda a historicidade, a qual Foucault reserva o termo a priori histórico. Talvez este seja o modo de objetivação que melhor caracteriza a noção de épistémè, e, no limite, pode-se dizer que ele determina o objeto de análise da arqueologia foucaultiana. Em seus primeiros trabalhos, Foucault emprega o termo a priori concreto e a partir de Les mots et les choses passa a designar com maior precisão, o a priori histórico como condição de possibilidade de existência. Como pontua Foucault, "esse a priori [histórico] é aquilo que, numa dada época, recorta na experiência um campo de saber possível, define o modo de ser dos objetos que aí aparecem (...) e define as condições em que se pode sustentar um discurso reconhecido como verdadeiro" (FOUCAULT, 1969, p.171). Segundo esta afirmação, o a priori histórico 'autoriza e governa' as condições de possibilidade da experiência (empiricidades) e do saber (positividade). A ideia de um a priori constituinte das experiências de um saber possível remete diretamente a Kant, algo que Foucault reconhece e se esclarece a respeito:

Justapostas, as duas palavras provocam um efeito um pouco gritante; quero designar um a priori que não seria condição de validade para juízos, mas condição de realidade para enunciados (...) a priori, não de verdades que poderiam nunca ser ditas, nem realmente apresentadas à experiência, mas de uma história determinada, já que é a das coisas efetivamente ditas (...) A razão para se usar esse termo um pouco impróprio é que esse a priori deve dar conta dos enunciados em sua dispersão (...) do fato de que o discurso não tem apenas um sentido ou uma verdade, mas uma história, e uma história específica que não o reconduz às leis de um devir estranho (...) Além disso, o a priori não escapa à historicidade: não constitui, acima dos acontecimentos, e em um universo inalterável, uma estrutura intemporal; define-se como o conjunto das regras que caracterizam uma prática discursiva: ora, essas regras não se impõem do exterior aos elementos que elas correlacionam (...) $\mathrm{O}$ a priori das positividades não é somente o sistema de uma dispersão tem- 
poral; ele próprio é um conjunto transformável (FOUCAULT, 1969, p.16768).

Nesta longa explanação, Foucault apresenta seu posicionamento em relação à filosofia transcendental kantiana, pontuando a diferença entre o aspecto formal e o existencial da noção de a priori. Da perspectiva dada por Foucault, enquanto o a priori formal kantiano se vincula ao sujeito transcendental que, por conseguinte, se encerra em uma ideia de subjetividade universal (razão pura), o a priori foucaultiano está condicionado à historicidade das contingências epistêmicas, manifestada em um projeto de descrição dos acontecimentos discursivos em suas singularidades (FOUCAULT, 1969, p.39). Isso se revela na afirmação de Foucault: "uma coisa em todo caso é certa: é que o homem não é o mais velho problema nem o mais constante que se tenha colocado ao saber humano (...) pode-se estar seguro de que o homem é aí uma invenção recente" , cuja conclusão dessa sentença é conhecida "o homem é uma invenção que a recente data a arqueologia de nosso pensamento mostra facilmente. E talvez o fim próximo (...) então se pode apostar que o homem se desvaneceria como, na orla do mar, um rosto de areia" (FOUCAULT, 1966, p.398; Cf. no mesmo sentido p.319).

Enfim, têm-se dois momentos dedicados a Kant: a interpretação da filosofia kantiana (empíricotranscendental; sono antropológico) e a apropriação de termos kantianos à sua própria filosofia (condições de possibilidade $a$ priori). À questão kantiana: 'o que é o Homem?' a arqueologia contrapõe críticas ao discurso antropocêntrico. Com isso, percebe-se uma a estratégia de Foucault para desenvolver sua filosofia, a saber, 'colocar em questão' a pergunta que orienta uma reflexão filosófica. Resta saber como esse 'colocar em questão' contribui para o exercício de um pensamento crítico.

\section{As objeções de Béatrice Han:} Foucault colocado em questão

A fim de cumprir o propósito sobre o 'colocar em questão' na filosofia foucaultiana, parece ser necessário que neste artigo conste, mesmo que brevemente, os apontamentos e controversas trazidas por Han, devido à importância que seu comentário suscita. Nesse sentido, talvez o ponto mais relevante a ser observado seja a leitura que a comentadora faz da obra do filósofo francês, indagando se a filosofia de Foucault apresenta 
a devida coerência. Isso faz com que Han procure determinar qual é a questão central do pensamento foucaultiano. Se por um lado isso pode parecer uma tarefa ingrata, por outro lado tal esforço não merece ser menos apreciável. Por isso, divido a análise em dois momentos: primeiro, os apontamentos de Han sobre a filosofia de Foucault e a seguir as controversas suscitadas por tal maneira de interpretar.

Béatrice Han [agora Han-Pile] é uma comentadora com grande experiência nos estudos sobre Foucault. Seu principal trabalho é sua tese de doutorado, L'ontologie manquée de Foucault: entre l'historique et le transcendental (1998), que recebeu uma revisão para a publicação em idioma inglês, Foucault's critical project: between the transcendental and the historical (2002). A introdução da obra já oferece uma perspectiva do argumentado elaborado pela comentadora. Seguindo a padronizada divisão da pesquisa de Foucault, a fase da arqueologia do saber, a genealogia política das relações de poder, e o chamado 'último Foucault' sobre a subjetividade ética, Han se pergunta se há uma questão central que pode "restituir à obra de Foucault a coerência de um projeto único?" (HAN, 1998, p.07). Se há "como afirmar que ela [a filoso- fia de Foucault] trata sempre do 'mesmo problema'” , a hipótese lançada por Han é de que "se o projeto foucaultiano é coerente, deve ser possível articulá-lo em torno de um tema único e central, aos quais os outros poderiam ser subordinados" (HAN, 1998, p.08).

A questão trazida por Han figura nos últimos anos de reflexão de Foucault, nos quais se percebe o interesse do autor em unificar um tema para sua pesquisa. Contudo, Han rejeita o 'olhar retrospectivo' que Foucault faz de sua obra, ou seja, a indicação do próprio autor em como ser lido ou estudado, e procura um tema que se sustente ao longo de toda a pesquisa foucaultiana. O tema encontrado por Han é o que ela define como o a priori histórico. Segundo Han, esta questão se faz presente desde os primeiros textos de Foucault, e diz respeito às condições de possibilidade da experiência possível. Para a comentadora, esta questão corresponde à introdução feita por Foucault de um termo paradoxal, o a priori histórico. Trata-se, para Han, de um "projeto [filosofia de Foucault] de encontrar a questão das condições de possibilidade do conhecimento uma resposta válida, sob a forma dessa renovação do tema transcendental que constitui a noção de a priori histórico" (HAN, 1998, p.14). No limite, pode-se di- 
zer que o a priori histórico representa uma tentativa de Foucault de 'historicizar' o transcendental, para assim poder fundar as condições de possibilidades do saber na contingência histórica. Nas palavras de Han, Foucault estabelece "a hipótese de um a priori totalmente dado na história, que se transforma com ela, e que de alguma maneira se encontra mais além na definição das condições de possibilidade, elas mesmas variáveis, do qual o conhecimento de uma época pode e deve formar a si mesmo" (HAN, 1998, p.12).

A partir de uma pesquisa orientada pelo a priori histórico, Han considera que uma parte crucial do projeto de Foucault se torna o problema de prover uma formulação coerente do a priori histórico da experiência. Porém, devido à confusão paradoxal do a priori histórico, Han avalia que o pensamento de Foucault acaba por ficar preso na tensão empíricotranscendental que ele mesmo critica. Na leitura proposta por Han, a fase genealógica de Foucault procura redefinir o a priori histórico a partir de noções como 'domínio de objetos' e 'regimes de verdade' (HAN, 1998, p.17-8). Devido à tensão entre o transcendental e o histórico (HAN, 1998, p.21), e a necessidade de uma resposta a essa questão, Han alega que Foucault teve que reintrodu- zir a noção de um sujeito constitutivo de si em seus modos de subjetivação. No chamado 'último Foucault', o a priori histórico se manifesta sob a forma de noções como 'problematizações' e 'jogos de verdade', algo que, para Han, indicam a derradeira tentativa de o filósofo francês restabelecer o tema transcendental na empiricidade histórica. Tal argumento conduz Han a afirmar que:

Seguindo esta lógica retrospectiva, o percurso foucaultiano pode então se decifrar em seu conjunto como a passagem da interrogação arqueológica sobre condições as quais um sujeito pode dizer a verdade à ideia genealógica segundo a qual a verdade é em si mesma a condição de possibilidade maior da constituição de si como sujeito (HAN, 1998, p.22).

Acerca da tensão históricotranscendental desencadeado pelo a priori histórico foucaultiano, a resposta encontrada por Han é que o projeto de Foucault falha ao tentar 'historicizar' o transcendental, ou seja, não pode oferecer formas de constituição da subjetividade apenas expondo 
condições de possibilidades empíricas. Portanto, não somente a filosofia de Foucault se apresenta incoerente em relação à questão central alegada por Han, como não supera a irredutibilidade do campo transcendental com o domínio empírico da história.

A despeito das diversas tentativas constituídas pelas noções de 'épistémè', de 'arquivo', de 'regime discursivo', de 'jogos de verdade' ou ainda de 'problematização', Foucault não conseguiu dar uma versão satisfatória do antigo a priori histórico husserliano (...) chocou-se de maneira recorrente com diferentes figuras dos duplos antropológicos outrora analisados. A cada vez reavivado pelos choques sucessivos, a tensão entre o histórico e o $a$ priori acabou por usar o belo e corajoso projeto de "historicizar" o transcendental, enquanto não sem certa ironia, o arqueólogo reencontrou, ao fim de seu percurso, o problema que inicialmente lhe havia servido como alvo a rebater, quer dizer, aquele do sujeito: ainda que sempre desejasse remarcar e multiplicar as tomadas de posições historicizantes, Foucault reencontra uma última vez a perspectiva transcendental através do tema de uma autoconstituição livre e autônoma do sujeito por si mesmo (HAN, 1998, p.320).

Vale ainda destacar que parte da argumentação de Han se apoia sobre a leitura da Thèse Complémentaire, a qual serve como prova do interesse de Foucault pela filosofia transcendental (HAN, 2003). Segundo a interpretação de Han sobre a Thése Complémentaire, Foucault critica Kant por ter confundido a questão da filosofia transcendental. Por um lado, a fase Crítica fundamenta o Homem nas condições de possibilidade da experiência no domínio transcendental (para Foucault, o universal); por outro lado, a obra Antropologia de Kant determina o Homem pelas condições de possibilidade da experiência no domínio empírico (para Foucault, a finitude).

Não obstante, em Les mots et les choses, Foucault recaí na mesma confusão que procura criticar. Han retoma esse assunto no texto, The 'death of man': Foucault and the anti-humanism (HAN, 2010), no qual explora dois sentidos que o termo Homem pode assumir. 
Um primeiro sentido é arqueológico, com o qual Foucault se refere ao Homem como acontecimento epistêmico, ou seja, seu aparecimento no domínio do saber a partir do final do século XVIII. Um segundo sentido é existencial, com o qual Foucault se refere ao Homem como indivíduo 'governado' pelo seu corpo, seu trabalho e sua linguagem. Embora Han reconheça que esta distinção é meramente formal, afirma que ela pode auxiliar no entendimento sobre qual referência se aplica o sentido do termo Homem. O primeiro sentido proposto se direciona à noção de a priori histórico; o segundo sentido mencionado se dirige às empiricidades da vida, do trabalho e da linguagem. Para Han, "como sugerido (...) a prática da arqueologia em Les mots et les choses talvez seja melhor caracterizada como uma forma de 'história transcendental'” (HAN, 2005, p.600).

Enfim, a interpretação que Han faz da filosofia de Foucault assume o a priori histórico como uma versão revisada e não-subjetiva do transcendental: "então, o problema é saber se, nessa retomada da questão crítica e nessa reformulação historicizante do tema transcendental, Foucault realmente obtém êxito ao evitar as 'ilusões antropológicas' denunciadas pelo Com- mentaire [Thèse Complémentaire]" (HAN, 1998, p.07).

A leitura realizada por Han, pode-se dizer, parece ser bastante perspicaz, e com isso auxilia a melhor compreender qual o sentido sobre o 'colocar em questão' no pensamento de Foucault. Não obstante, a ideia de interpretar a pesquisa do filósofo francês sob a perspectiva do a priori histórico e sua tentativa falha (como sugere o título de sua obra) de 'historicizar' o transcendental não deixa de suscitar controversas. É preciso informar que Han apresenta uma leitura que acompanha o trabalho de Dreyfus e Rabinow, Michel Foucault: beyond structuralism and hermeneutics (1985). Esta obra analisa a filosofia de Foucault com várias referências às questões da fenomenologia, sobretudo a de Heidegger. Entretanto, o referencial utilizado por Han para comparar a obra de Foucault é a filosofia transcendental de Husserl, mais do que Kant. Assim como os apontamentos, as controversas também têm seu valor; por isso, observa-se três comentários acerca do trabalho de Han.

Em sua análise, Colin Koopman (2010) chama a atenção para os estudos que interpretam Foucault por meio de 'lentes fenomenológicas' (LEBRUN, 1992); no caso de Han, Koopman afirma que ela faz uma interpretação do 
método arqueológico em termos de uma fenomenologia históricotranscendental. No entanto, a ideia de Han encontra duas dificuldades: a primeira é indexar Foucault à tradição da fenomenologia francesa; de fato, autores como Bachelard, Cavaillès, Canguilhem são citados por Foucault como precursores de seu trabalho, porém tantos outros parecem ser ainda mais influentes. A segunda dificuldade é encontrar em Foucault traços da experiência vivida (vécu), tarefa fundamental para a fenomenologia existencial.

O comentário de Marc Kelli (2004) assinala a interessante estratégia adotada por Han de descrever as mudanças do a priori histórico feitas por Foucault ao longo de seu percurso filosófico. Contudo, uma vez que Han admite o a priori histórico como guia de seu estudo, Kelli observa que há uma tendência da autora em interpretar 'três fases arqueológicas' da pesquisa foucaultiana. Para Kelli, "na medida em que Han não acha o tema central que ela procura, ela não toma isso como um sinal de que há algo de errado com sua tese, mas antes que há alguma coisa de errado com Foucault" (KELLI, 2004, p.06).

Por fim, Gary Gutting (2003) aponta para a insistência de Han em ver conexões entre a arqueologia e a fenomenologia, sobretudo a de Husserl. A ideia de que Foucault quer 'historicizar' o transcendental parece estranha a Gutting. Exemplo disso aparece na obra de Foucault Surveiller et punir (1975), a qual Han descreve como um trabalho puramente empírico que tenta evitar o tema transcendental. Porém, essa objeção tem força somente se admitido que a genealogia necessita de uma fundamentação estritamente filosófica, e isso quer dizer, feita por filósofos. Segundo Gutting, isso se deve ao fato de Han manter por alguma razão a convicção de que a filosofia transcendental é um projeto filosoficamente inevitável. A própria premissa colocada por Han é, nesse sentido, duvidosa; conceber que um projeto filosófico para ser coerente necessariamente tem que ter um tema único e central que possa subordinar todas as outras questões parece ser, no mínimo, uma perspectiva controversa. Para Gutting (2003), "Han simplesmente assume que Foucault deve ter um projeto transcendental em mente".

\section{O que é o Homem... que nós mes- mos somos?: sobre o 'colocar em questão'}

A despeito das convicções de Han, sua tese auxilia a apreender o sentido do 'colocar em questão' na fi- 
losofia de Foucault. Seus apontamentos têm como ponto positivo captar as imprecisões de Foucault e direcionar objeções que então surgem quando se interpreta a filosofia do filósofo francês a partir de certa perspectiva. Não obstante, a controversa que esse procedimento pode criar indica os perigos de reduzir todo o pensamento foucaultiano, como quer Han, a um paradigma ou sistema filosófico, no seu caso a fenomenologia. Com isso, corre-se o risco de desprezar ganhos teóricos e conceituais que indiscutivelmente a filosofia de Foucault produz. Portanto, primeiramente cabe apresentar um contraponto à interpretação de Han; na sequência, propõe-se elaborar um argumento sobre como 'colocar em questão' na filosofia de Foucault; por fim, segue-se algumas considerações.

Considero que as análises de Han buscam seu fundamento principalmente devido à fase arqueológica de Foucault. Embora Han não mencione os modos de objetivação da épistémè, nela, como já visto, Foucault desenvolve três condições de possibilidades: de experiência na empiricidade, de exercício na positividade e de existência no a priori histórico. Han trabalha indistintamente com estes modos de objetivação. Talvez nesse ponto falte uma observação mais atenta e de grande importância para o pensamento foucaultiano, a saber, o que tais modos de objetivação vêm discutir. A comentadora se esforça para extrair do a priori histórico uma filosofia transcendental; contudo, nesse processo sacrifica (pois não discute) a orientação feita por Foucault de que a arqueologia visa desfazer as sujeições do discurso antropocêntrico. Dessa forma, o a priori histórico, embora não recuse servir de condição de possibilidade para o surgimento de tal discurso, permite a Foucault buscar as implicações de um 'jeito próprio de questionar' que o autor reconhece em Kant sua forma mais arrematada.

Para Foucault, as implicações de um discurso sobre universais antropocêntricos não são verdades absolutas de qualquer razão humana; daí a incursão do autor nas tecnologias de biopoder, tanto disciplinar quanto biopolítico, para entender de que forma tais discursos circulam, como são apropriados e distribuídos, quais estratégias e táticas possuem, especialmente nas relações sociais institucionalizadas. Enquanto Han entende Foucault preso na reformulação do a priori histórico, nota-se que o arqueólogo francês não faz das condições de possibilidade a ultima ratio de seu pensamento. Foucault procura compreender como os discursos se le- 
gitimam e se exercem em subjetividades concretas: o louco, o delinquente, o homossexual. Em nenhum desses casos, Foucault recorre à ideia de um sujeito soberano doador de sentido que unifique a todos e a todos possa representar. De acordo com O'Leary (2008, p.12): "não se trata de buscar o a priori kantiano, mas o a priori histórico; e não toda experiência possível, mas a experiência historicamente singular" . Não se trata, portanto, de um sujeito transcendental que sustenta as condições de possibilidade da experiência; antes, é a experiência que explica a emergência histórica de tipos singulares de subjetividade. As condições de possibilidade apresentam em sua história, em seu a priori histórico, relações de poder produzidas simultaneamente. Como diz Foucault (1975, p.224): “as 'Luzes' que descobriram a liberdade inventaram também as disciplinas". Nesse sentido, o autor não reformula a questão transcendental das condições de possibilidade como defende Han, uma vez que a genealogia foucaultiana já assume que o Homem da modernidade não pode ser pensado na ausência da malha institucional que o captura.

Essa articulação entre o discurso antropocêntrico e as tecnologias de biopoder recebe uma importância do autor que se mantém constante em quase toda sua filosofia, na medida em que Foucault mobiliza diferentes métodos, instrumentos conceituais, campos de pesquisas. Enfim, se como alega Han há alguma falha ou falta (manquée) na filosofia de Foucault, não parece ser por postular uma historicidade do transcendental, considerando que a pesquisa foucaultiana não atende a premissa de tema único e central estabelecido pela comentadora. De fato, não se nega que a questão da filosofia transcendental possa ser encontrada nos estudos de Foucault; o que se recusa é o olhar reducionista. A leitura de Han segue deliberadamente o lema da fenomenologia, 'voltar às coisas mesmas', algo que a arqueogenealogia de Foucault certamente contesta.

Como apresentado no 'triedro kantiano', razão crítica, filosofia transcendental e Esclarecimento [Aufklärung] podem ser entendidos como base da reflexão de Kant. Ainda, a filosofia transcendental não se restringe a prover garantias às condições de possibilidade da razão humana; para Kant, sua filosofia se outorga o direito de colocar questões que devem ser respondidas, seja como são possíveis os juízos sintéticos $a$ priori?; seja a derradeira questão: o que é o Homem? Ora, o pensamento de Foucault manifesta seu interesse por tais temas kantianos; 
contudo o autor progride para um estágio em que extrapola, mas não ignora, as condições de possibilidade da experiência em favor de certas singularidades históricas. Pode-se dizer que a filosofia de Foucault procura entender, por vários meios, não apenas o que torna a questão do Homem possível; procura também entender por quais razões esta questão se torna a mais necessária.

Portanto, a tese de Han serve de exemplo para melhor entender o sentido do 'colocar em questão' na filosofia de Foucault. Ao contrário do que pensa a comentadora, não parece ser o caso que as tensões trazidas por Foucault entre Crítica-Antropologia, entre empírico-transcendental, se resolvam em si mesmos. No pensamento foucaultiano está em questão justamente o 'colocar em questão'. Não é que tais tensões simplesmente devem ficar sem respostas; trata-se, porém, de observar que tais tensões devem pertencer à outra questão: quem somos nós atualmente?

Como visto, os primeiros trabalhos do filósofo francês se dedicam a analisar criticamente as implicações trazidas pelo sono antropológico. Porém, em seus últimos anos de pesquisa, Foucault afirma, talvez até de modo surpreendente, que seu pensamento pertence à tradição de Kant. Essa declaração se deve ao fato de Foucault diferenciar dois modos de 'colocar em questão' que encontram em Kant seu expoente. Segundo Foucault, "Kant colocou, fundou essa tradição da filosofia crítica que coloca a questão das condições de possibilidade em que o conhecimento verdadeiro é possível" de modo que "é essa forma de filosofia que vamos encontrar agora na filosofia, digamos, analítica anglo-saxã" (FOUCAULT, 2008, p.21). Prossegue o autor: "mas existe, no interior da filosofia moderna e contemporânea, outro tipo de questão, outro modo de interrogação categórica: a que vemos nascer justamente na questão da Aufklärung" ; trata-se de "uma tradição que coloca a questão de: o que é atualidade? qual o campo atual de nossas experiências possíveis?" - A resposta de Foucault é de que "tratar-se-ia do que poderíamos chamar de uma ontologia do presente, ontologia de nos mesmos" - Logo, Foucault conclui que "é essa forma de filosofia [ontologia de nós mesmos] que, de Hegel à Escola de Frankfurt, passando por Nietzsche, Max Weber, etc., fundou uma forma de reflexão à que, é claro, eu me vinculo na medida em que posso" (FOUCAULT, 2008, p.22).

O que importa observar dessa afirmação é o fato de que, se Foucault se refere à 'dois Kant', isso 
se deve justamente ao modo de 'colocar em questão'. Isso significa reconhecer o que pode-se chamar de um kantismo de Foucault a partir da potencialidade de 'colocar em questão'. Se por um lado Kant questiona o conhecimento verdadeiro, isto é, a razão; por outro lado também questiona o presente, ou seja, a história. Ora, razão e história encontram sua articulação no que Kant denomina Aufklärung. Em uma espécie de texto-testemunho, Qu'est-ce que les Lumières? (1984), Foucault declara que "não existe quase nenhuma filosofia que, direta ou indiretamente, não tenha sido confrontado com esta mesma questão: qual é então esse acontecimento que se chama a $A u f$ klärung e que determinou, pelo menos em parte, o que somos, pensamos e fazemos hoje?" (FOUCAULT, 1994, IV, p.562). Para Foucault, "Kant define a Aufklärung de uma maneira quase inteiramente negativa, como uma ausgang, uma 'saída', uma 'solução'" , de modo que "a questão se refere puramente à atualidade (...) ele [Kant] busca uma diferença: qual a diferença que se introduz hoje em relação à ontem?" (FOUCAULT, 1994, IV, p.564). Pode-se perceber que enquanto Kant articula razão e história, Foucault atrela o acontecimento à atualidade, e com isso propõe uma ra- dicalidade maior do que há em Kant, na medida em que busca a diferença do acontecimento a partir do que ele tem de atual. Portanto, é no domínio da historicidade, o qual Han chama de a priori histórico, e não do transcendental, que Foucault busca as condições de possibilidade da atitude de 'colocar em questão' o acontecimento da atualidade: quem somos nós?

A noção de historicidade é constante na pesquisa de Foucault, tanto que muitas de suas obras são intituladas história (da loucura, da sexualidade) ou nascimento (da clínica, da prisão, da biopólitica). Trata-se, porém, de uma concepção específica de história proposta por Foucault que não seja sustentada por uma noção de verdade absoluta ou por universais antropocêntricos (FOUCAULT, 1969, introdução). Na medida em que Foucault prepara suas obras para colocar questões de pertinências históricas, ao invés de problemas metafísicos, percebe-se um claro e manifesto movimento feito pelo autor para se afastar da filosofia da história (sobretudo hegeliana) e suas concepções contínuas, progressistas e totalizantes que postulam uma visão de mundo acerca de uma época. Como sugere Han, há certa relação de apropriação da filosofia transcendental kantiana por Foucault, mas parece questionável di- 
zer que a intenção do arqueólogo francês seja reviver o projeto de uma fenomenologia transcendental77. Importa considerar, por essa razão, que a historicidade é a própria condição de possibilidade de 'colocar em questão'; a historicidade em Foucault é, dessa maneira, a história das práticas e experiências que constituem a subjetividade do Homem ocidental.

Para tanto, o filósofo francês se apoia em um conceito que desenvolve na fase final de sua pesquisa, a saber, o si mesmo (soi), presente em termos como práticas de si, técnicas de si. Mais do que pronome reflexivo, o si mesmo (soi) foucaultiano designa uma experiência, uma relação de si mesmo constitutiva da subjetividade. Nesse sentido, Foucault reconhece que em suas pesquisas genealógicas e arqueológicas lhe incomodou a pouca importância atribuída à subjetividade (FOUCAULT, 1994, IV, p.697). Realizar uma história da subjetividade significa recusar a ideia de uma subjetividade universal dotada de verdades absolutas da razão. Segundo Foucault, a Aufklärung enfatiza "um tipo de interrogação filosófica que problematiza [coloca em questão] simultaneamente a relação com o presente, o modo de ser histórico e a constituição de si próprio [subjetividade]" a partir da "reativação permanente de uma atitude [crítica]: ou seja, um ethos filosófico que seria possível caracterizar como [atitude] crítica permanente de nosso ser histórico" (FOUCAULT, 1994, IV, p.571). Atitude crítica e ethos filosófico (Aufklärung) são palavraschave para compreender a apropriação por parte de Foucault de termos kantianos, e ao mesmo tempo, entender a transformação dessas palavras-chave em conceitos foucaultiano. Como diz Foucault:

Um ethos filosófico consiste em uma [atitude] crítica do que dizemos, pensamos e fazemos, por meio de uma ontologia histórica de nós mesmos (...) a crítica [kantiana] é certamente a análise dos limites e a reflexão sobre eles. Mas, se a questão kantiana era saber a que limites o conhecimento deve renunciar a transpor, parece-me que, atualmente, a questão crítica

\footnotetext{
7 Segundo Foucault, o pensamento fenomenológico de Edmund Husserl (especialmente em sua obra inacabada Krisis der europäischen wissenschaften, 1936) representa o projeto do desenvolvimento universal da razão ocidental a partir da positividade das ciências e a radicalidade da filosofia. Nesse sentido, Les mots et les choses pode ser entendida como uma leitura "anti-Krisis" husserliana. Cf. FOUCAULT, 1994, IV, p.767.
} 
deve ser revertida em uma questão positiva (...) tratase, em suma, de transformar a crítica exercida sob a forma de limitação necessária em uma crítica prática sob a forma de ultrapassagem possível (FOUCAULT, 1994, IV, p.574).

Percebe-se que Foucault trata como função da Aufklärung, acontecimento atual de um ethos filosófico, efetuar uma atitude crítica, que não seja restrita aos discursos antropocêntricos da verdade absoluta, mas que se oriente a interpretar as relações entre o saber, o poder e a experiência de si mesmo (soi), tanto que Foucault atribui como tarefa da filosofia realizar uma crítica da razão política (FOUCAULT, 1994, IV, p.134). Logo, Foucault é categórico ao esclarecer como se relaciona a função da atitude crítica com seu pensamento: "Nesse sentido, essa [atitude] crítica não é transcendental e não tem por finalidade tornar possível uma metafísica: ela é genealógica em sua finalidade e arqueológica em seu método" (FOUCAULT, 1994, IV, p.574).

Ora, como já visto em Les mots et les choses, Foucault confere a Kant a 'inauguração' da épistémè moderna, devido aos mo- dos de objetivação; na mesma medida, expõe a confusão empíricotranscendental que gera o sono antropológico da modernidade. Esta constatação não se apaga ou se contradiz com o fato de Foucault retomar a Aufklärung kantiana; não se trata de refazer a interpretação a Kant, mas antes de recuperar para sua filosofia o pensamento crítico.

Pode-se sem dúvida dizer que ele [pensamento crítico] nos vem pela abertura praticada por Kant na filosofia ocidental, no momento em que ele articulou, de um modo ainda bem enigmático, o discurso metafísico e os limites de nossa razão. O próprio Kant acabou por fechar essa abertura ao reduzir, no final das contas, toda interrogação crítica a uma questão antropológica (FOUCAULT, 1994, I, p.239).

O pensamento crítico foucaultiano pode ser definido por 'colocar em questão' a interrogação antropológica: o que é o Homem? Para responder tal pergunta, a filosofia transcendental kantiana recorre à subjetividade universal e aos ideais da razão 
(FOUCAULT, 1994, IV, p.411). Parece ser equivocado afirmar que Foucault mantém a pretensão de responder esta pergunta simplesmente substituindo os princípios de Kant por conceitos como historicidade (a priori histórico) e experiência de si mesmo (soi). Nos estudos de Foucault, esses conceitos têm a função de preparar e conduzir o pensamento crítico a uma nova questão filosófica que, como quer Foucault, ultrapasse o limite que ainda lhe serve de condição de possibilidade. A questão: 'o que é o Homem?'... pode ter seu sentido transformado quando se completa em: ...'que nós mesmos somos?'. Como observa Frédéric Gros, este é um tipo de interrogação presente nos trabalhos de Foucault: "quem somos nós, que para sermos nós mesmos, sujeitos dotados de razão, temos necessidade de confinar os loucos? (História da loucura), quem somos nós, que, para sermos nós mesmos, construímos fortalezas para delinquentes? (Vigiar e punir)" (GROS, 1995, p.178).

Por essa razão, entende-se a insistência de Foucault em afirmar uma ontologia de nós mesmo: "é preciso concebê-la como atitude, um ethos, uma via filosófica em que a crítica do que somos é simultaneamente análise histórica dos limites que nos são colocados e prova de sua ultrapassagem possível" (FOUCAULT, 1994, IV, p.577). Portanto, não se considera apenas a historicidade do Homem em seu conteúdo epistêmico, isto é, as condições de possibilidade de experiência, como estabelecido pela filosofia transcendental kantiana. Trata-se, antes, de um pensamento crítico sobre o Homem como forma de questão.

À guisa de conclusão, a hipótese sustentada por Han de reduzir as pesquisas de Foucault à pretensão de 'historicizar o transcendental' parece em alguns pontos equivocada, sobretudo quando considera que a historicidade desempenha apenas a função transcendental. Certamente, há dificuldades quando considerado que Foucault pretende responder a questão: 'o que é o Homem?' a partir de um a priori histórico, empírico e contingente. No entanto, a interpretação da filosofia de Foucault pode ser feita de outras maneiras, as quais privilegiem temas como as sujeições antropocêntricas, as tecnologias de poder ou a ontologia de nós mesmos. A partir desse ponto, encontra-se maior facilidade, e também familiaridade, para compreender de que modo a questão sobre 'o que é o Homem?' permite 'colocar em questão' uma nova pergunta de pesquisa. Han acerta quando relaciona a filosofia transcendental que define as condições de possibili- 
dade de experiência com aspectos da filosofia de Foucault, sobretudo se observado o conceito de épistémè. Mesmo assim, ela parece desconsiderar a preocupação de Foucault com os modos de objetivação/subjetivação que servem de background (plano de fundo) constante em suas obras. Han lê o a priori transcendental a sério, isto é, universal e categórico, e encontra inconsistências na noção foucaultiana de história por lidar com contingências e acontecimentos. Entretanto, a comentadora não discute a historicidade como possibilidade de questionamentos, algo que se encontra por toda a filosofia de Foucault ao se analisar as práticas discursivas, práticas de sujeição e práticas de si mesmo. As objeções de Han acerca da falta de coerência na obra de Foucault parece se confundir com uma exigência de fidelidade temática. De fato, o pensamento do filósofo francês não prima por teorias, mas por questões (problematizações como diz Foucault), e como observa Judith Revel, é possível extrair de obra foucaultiana uma coerência transversal ao inquerir o que pode produzir existências irredutíveis à linearidade e à normatividade da ordem estabelecida (REVEL, 2004, p.84).

Sem dúvida, a influência de Kant é marcante na obra de Fou- cault, seja direta ou indiretamente. Se a filosofia transcendental kantiana define tanto as condições de possibilidade quanto se outorga o direito de 'colocar em questão' a própria orientação filosófica, então o pensamento de Foucault acolhe na íntegra esse legado. Não se nega que Foucault procura investigar na história as condições de possibilidade do que nos tornamos no presente. Contudo, o mais importante é discernir que isso somente faz sentido à medida que tais condições de possibilidade podem ser 'colocadas em questão'. A questão: 'o que é o Homem?' se apresenta inquerida de várias maneiras ao longo do percurso de Foucault, na medida em que serve como orientação para se pensar tipos de subjetividades: o homem-louco, o homem-delinquente, homeminfame. Nesse sentido, quando ao fim de Les mots et les choses Foucault anuncia a suspeita da morte do Homem, não pretende repetir Nietzsche e apresentar sua superação, Übermensch o além-doHomem; o que faz Foucault é justamente problematizar, 'colocar em questão' a pergunta pelo 'o que é o Homem?'. Se a questão do Homem assinala o fim da filosofia, então o fim do Homem pode ser o começo no qual é de novo possível pensar (FOUCAULT, 1966, p.353). Enfim, há no pensamento de 
Foucault todo um desenvolvimento de interpretações, apropriações e questionamentos da filosofia kantiana; e talvez, justamente por isso, o pensador francês foi capaz de construir um modo de pesquisar e refletir evidentemente próprio que o qualifica como um dos principais nomes da história recente da humanidade. Se por um lado Foucault aceita a questão da filosofia transcendental, via antropologia kantiana: 'o que é o Homem?', por outro lado, recusa qualquer resposta que admita nessa questão a necessidade de formular filosofias do sujeito.
É próprio da filosofia de Foucault transformar a questão sobre 'o que é o Homem?', em um referencial para a sua questão filosófica: 'o que acontece com quem é o Homem atualmente?', e com isso, fazer da filosofia um diagnóstico do presente (FOUCAULT, 1994, I, p.606).

Para a filosofia, o campo da reflexão humana por excelência, e para o filósofo que se vê enlaçado pelo trabalho interpretativo de textos, é de fundamental importância saber elaborar a maneira de 'colocar em questão' um referencial de pesquisa.

\section{Referências}

ADORNO, T.; HORKHEIMER, M. Dialética do Esclarecimento. Rio de Janeiro: Editora Zahar, 1985.

CUSSET, F. Filosofia francesa: a influência de Foucault, Derrida, Deleuze \& cia. Porto Alegre: Editora Artmed, 2008.

FOUCAULT, M. Les mots et les choses: une archéologie des sciences humaines. Paris: Éditions Gallimard, 1966.

. L’Archéologie du savoir. Paris: Éditions Gallimard, 1969.

- Surveiller et punir: naissance de la prison. Paris: Éditions Gallimard, 1975.

. Dits \& Écrits. volumes/tomos I, II, III, IV. Paris: Éditions Gallimard, 1994.

. Le gouvernement de soi et des autres: cours au Collège de France

1982-83. Paris: Éditions Gallimard; Éditions du Seuil, 2008.

. "Thèse Complémentaire pour le doctorat" . Genèse et structure de l'Anthropologie de Kant. Paris: Vrin, 2008. Disponível em:

https://michel-foucault.com/links/kant.pdf. Acesso em: Dez/20 17. 
. A ordem do discurso. Aula inaugural no Collège de France. $22^{\mathrm{a}}$ ed.. Trad. de Laura Fraga de Almeida Sampaio. São Paulo: Editora Loyola, 2012.

GROS, F. "Foucault e a questão de quem somos nós?" . Tempo Social, Universidade de São Paulo, n 1-2, vol. 07, pp.175-178, 1995.

GROS, F.; DÁVILA, J. Michel Foucault: lector de Kant. Merida: Universidad de los Andes, 1998.

GUTTING, G. "Review of Béatrice Han's Foucault's Critical Project". Notre Dame Philosophical Reviews, May 2003. Disponível em:

. Acessado em: Dez/2017.

HAN, B. L'ontologie manquée de Michel Foucault: Entre l'historique et le transcendantal. Collection Krisis. Grenoble: Editions Jérôme Millon, 1998.

. "Is early Foucault a historian? History history and the Analytic of finitude". Sage Journal, Philosophy and Social Criticism, vol. 31, n 5-6, pp.585-608, 2005.

- Reply to Gary Gutting's review of Foucault's Critical Project: Between the Transcendental and the Historical. Disponível em:

. Acesso em: Dez/2017.

HAN [PILE], B. "Death of man: Foucault and the anti-humanism" . In: O'LEARY, T.; FALZON, C. Foucault and philosophy. Chichester: Wiley-Blackwell, pp.119-41, 2010.

KANT, I. Prolegómenos a toda a metafísica futura (que queira se apresentar como ciência). Trad. de Artur Morão. Lisboa: Edições 70, 1987.

Antropología en sentido pragmático. Trad. de José Gaos. Madrid: Alianza Editorial, 1991.

- Crítica da razão pura. Trad. de Alexandre Fradique Morujão. Lisboa: Fundação Calouste Gulbekian, 2001.

. Crítica da faculdade do juízo. Trad. de Valério Rohden; António Marques. Rio de Janeiro: Forense Universitária, 2012.

. "Resposta à pergunta: o que é Esclarecimento [Aufklärung]". In: Textos seletos. Trad. Danilo Marcondes. Petrópolis: Editora Vozes, 2013.

KELLY, M. "Review of Béatrice Han's Foucault's Critical Project" . Foucault Studies, $\mathrm{n}^{\circ}$ 01, pp.92-97, 2004.

KOOPMAN, C. "Historical Critique or Transcendental Critique in Foucault: Two Kantian Lineages" . Foucault Studies, n 08, pp.100$121,2010$. 
KRAEMER, C. Ética e liberdade em Michel Foucault: uma leitura de Kant. São Paulo. 288 fls. Tese de Doutorado em Filosofia. Universidade de São Paulo (USP), Faculdade de Filosofia, Letras e Ciências Humanas, 2008.

LACAN, J. Le Séminaire livre XI: Les quatre conceptes fondamentaux de la psychanalyse. Paris: Éditions du Seuil, 1973.

LEBRUN, G. "Notes on phenomenology in Les mots et les choses" . In: ARMSTRONG, T. J. (org.) Michel Foucault philosopher. New York: Harvest Wheatsheaf, pp.20-35, 1992.

MILLER, J. La pasion de Michel Foucault. Santiago de Chile: Editorial Andres Bello, 1995.

O'LEARY, T. "Foucault experience literature” . Foucault Studies, nº5, pp.05-25, 2008.

PEREZ, D. O. "O significado de natureza humana em Kant" . Kant ePrints, série 02, vol. 05, $\mathrm{n}^{\circ}$ 01, pp.75-87, 2010.

REVEL, J. "O pensamento vertical: uma ética da problematização" . In: GROS, F. (org.). Foucault: a coragem da verdade. São Paulo: Editora Parábola, pp.65-87, 2004.

Recebido: $10 / 01 / 2019$

Aprovado: $26 / 04 / 2019$

Publicado: $13 / 05 / 2019$ 